\title{
Electricity and the Census
}

\section{A Glance at the Machines That Make Our Decennial Inventory a Matter of Weeks Instead of Years}

By J. A. Stewart

T $\mathrm{HE}$ Fourteenth Federal Census covber 31,1919 , is a subject of vide interest. It is a colossal enterprise. An army of workers is required for it. More than these, it needs a complete scientific and mechanical corps and equipment.

But for the invention of machines capable of arranging and adding figures more rapidly than can be done by human hand and mind, the taking of a Federal hand and mind, the tald of a Federal

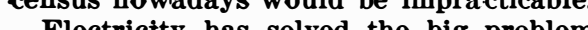
diectring the problem of digesting the schedules illed and sent in by the great host of enumerators in but the introductory part of the census. but the introductory part of the census. mere remans the vital work of acedrately compling tens of millions of schedIt and condensing them for publication. It is here that the mechanical powers came to the rescue. Invention has performed a tremendous service for the provision of needed Federal statistics. The old method of computing the facts contained in the census was by a laborious system of hand-tallying. Every fact relating to each person was indicated by a pencil mark under the proper heading on big sheets provided for the purpose. This plan was clumsy, slow and very
liable to error. So slow was the work that the last volume of the census of 1890 was not off the press until seven years after beginning the task of enumerating the population. In the Tenth Census (1880) the last of the volumes was published in 1889 . This represented a fair rate of speed, considering the dozens of bolky volumes required. But the lack of prompt publication seriously impaired the value of some of the most important statistics which were quite out of date before the public got them.

It was a former employee of the Bureau who invented the useful electric tabulating machinery which has proved such a boon to the statisticians of the Federal Census. This machinery was first used at the

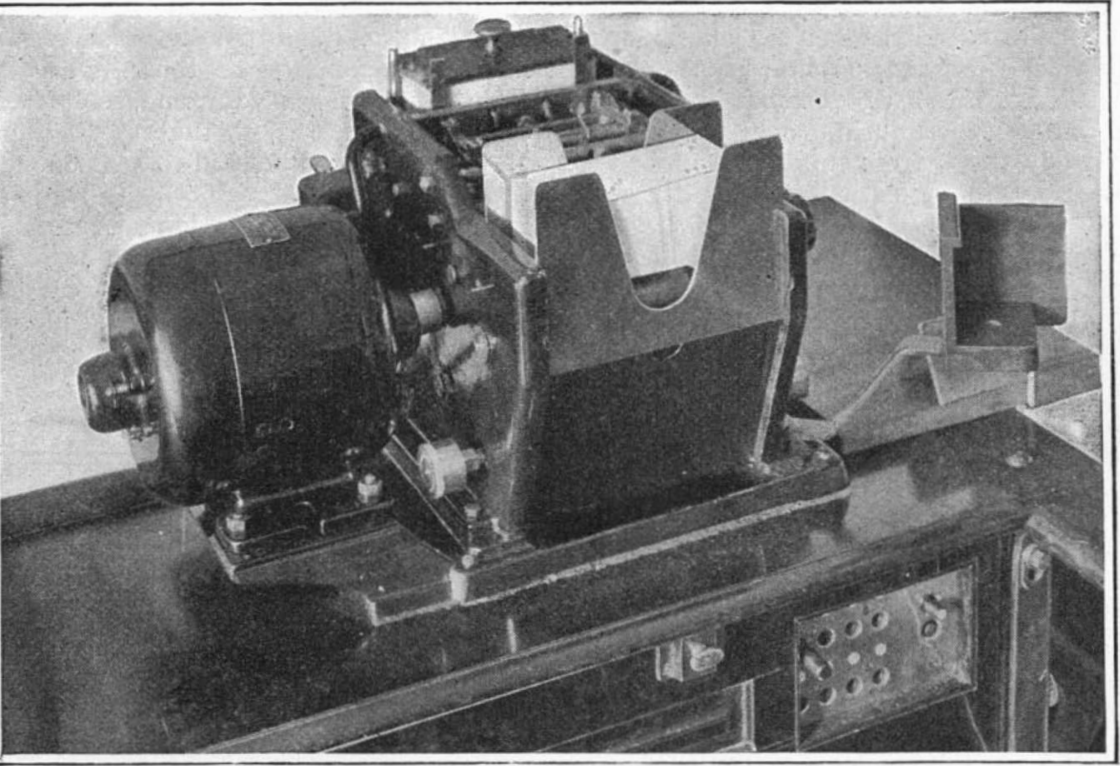

ic tabulating machine, showing automatic feed and stacks of cards in position before and after tabulation
Con Twelfth Census (1890), the director of which estimated that if the tallies of age, sex, nativity and occupation had been made by hand, it would have re quired the labor of one hundred clerks for seven years, eleven months and five days. It was found that electrical machinery saved nine-tenths of the time, two-thirds of the cost of hand work, and at least $\$ 5,000,000$ to the Government, besides being more accurate! In addition the machines enabled the census clerks to count combinations of facts.

Profiteers having secured control of these valuable machines the Director of the Census employed experts to invent electrical machinery for the work, Congress making an appropriation for the purpose. The Government had paid $\$ 750,000$ for the rental of the machines. With its own at the 13th census half a million dollars were saved.

The card-sorting and the cand-tabulating machinery of the census is simple highly perfected, and splendidly efficient In operating, the symbols for each are inserted by editors over the items in the various columns of the schedules to form divisions. The facts relating to race, birthplace and other subjects of inquiry are indicated on individual ords by punching holes through the cards corresponding to those on symbols Something like four million cards can be punched in a day by the army of clenks with the in a day by the army of clerks manine. The punched cards are autowherever ther is a pun in a card Wherer there is a punch in a card an blunt needle passing through the hole blunt needle passing through the hole into a cup of mercury and the fact is registered. On the machines frst used there was a series of dials from which the figures were copled on on "result slips" and fled for the compilng clerks. With the later machines this operation is entirely cut out. They are equipped with an automatic attachment for printin the totals (for each unit of area, district township, ward, city, county or state) and operate at the approximate rate of 24,000 cards an hour.

It will require about $110,000,000$ cards to record the population-a stack over ten miles high. As each of these cards is passed through the tabulating machines six times, more than half a billion electrical connections are made in tabulating the population of 1920 . Accuracy is the slogan of the Census Bureau. Each punching machine operator is watched to see that the wrong keys are not hit. And the alert tabulating machine with higher mechanical intelligence not only refuses to ring up when one of the insufficiently punched cards passes through but also stops until the offending rard is taken out. It is then up to the operator to go back to the schedules and supply the missing information.

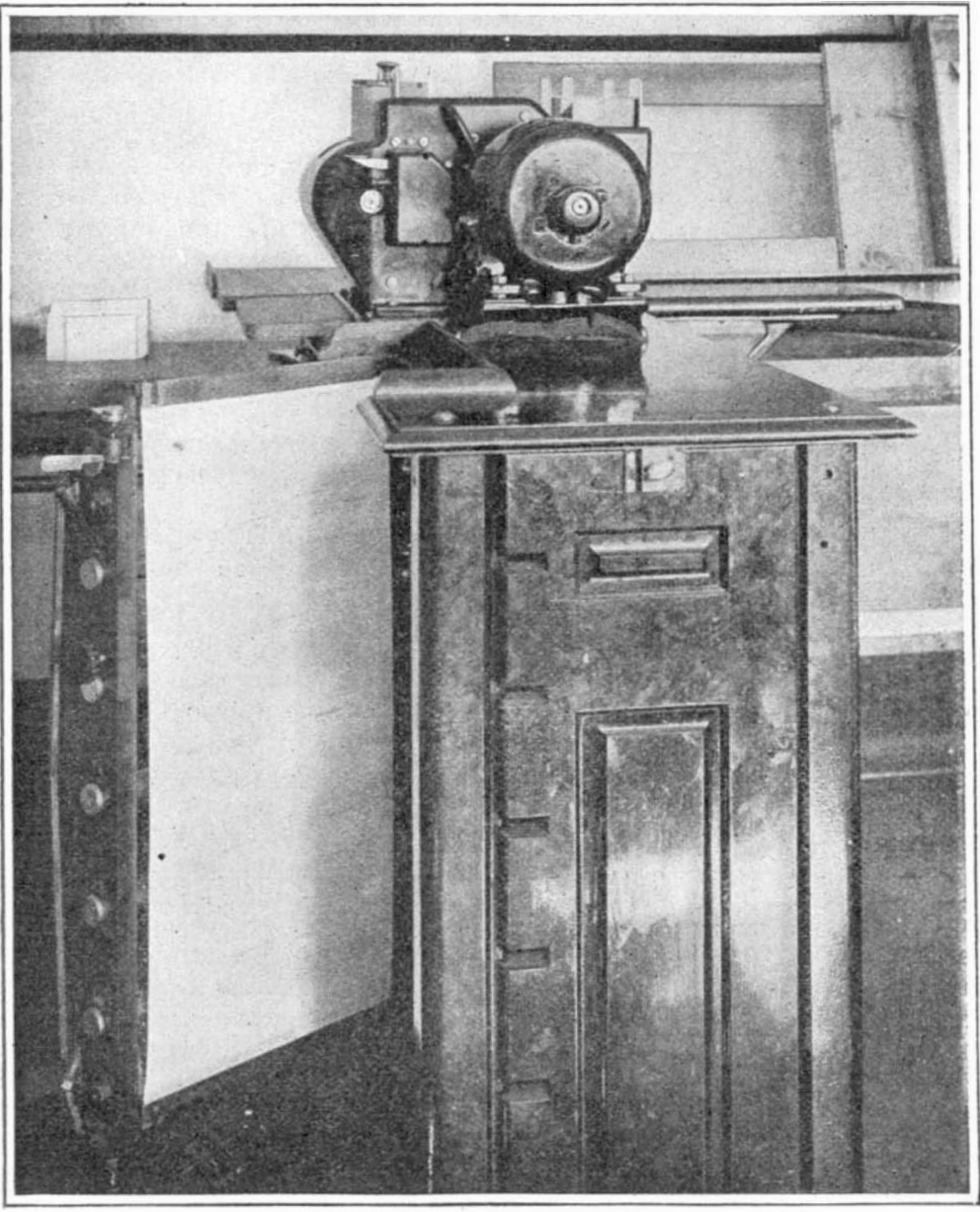

The tabulating machine, open to show the record sheet upon which it the totals from 60 counters, giving the details of each
of cards and the total number of each variety handled

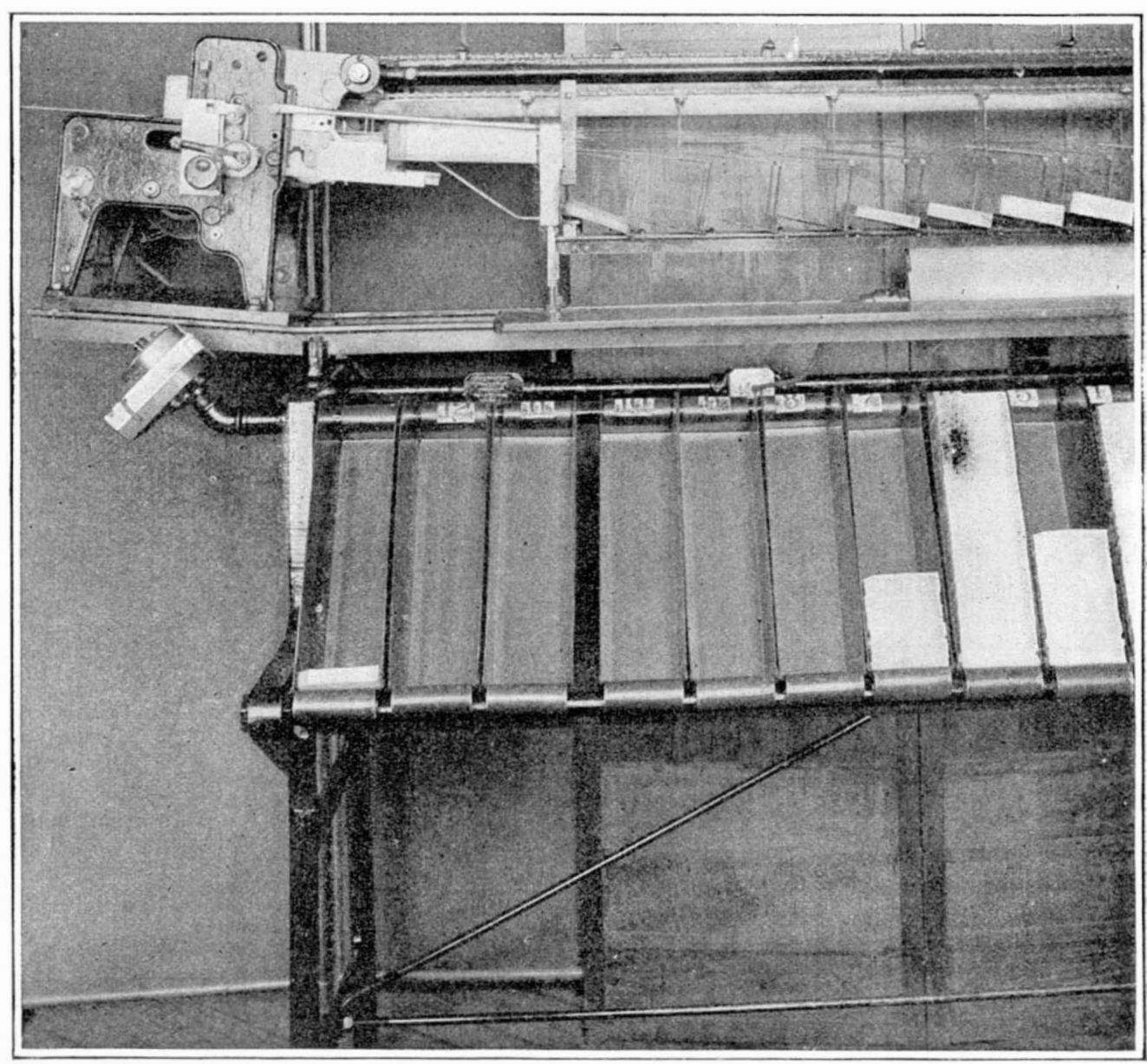

The machine that sorts the cards into any number of groups up to twelve, according to the data which they show. It handles 320 cards a minute, and rejects any that show impossible combinations of facts 